\title{
Jules Horowitz Reactor Irradiation Devices: Inspection Methods proposal
}

\author{
Seppo Hillberg ${ }^{1}$, François Baque ${ }^{2}$, and Stéphane Gaillot ${ }^{2}$ \\ ${ }^{1}$ VTT Technical Research Centre of Finland Ltd, Finland \\ ${ }^{2} \mathrm{CEA}$, France \\ Seppo.Hillberg@,vtt.fi
}

\begin{abstract}
Jules Horowitz Reactor (JHR) irradiation test devices (so called ADELINE and MADISON) must undergo a periodic inspection every 40 months (French ESP(N) Regulation). The first step of inspection proposal was performed from October 2019 to March 2020 and concerns application of non-destructive methods for electron beam welds, while examining the possible methods and locations that could be utilized.

This study has been performed in collaboration between VTT Technical Research Centre of Finland Ltd and French CEA with VTT employee secondment at CEA Cadarache. The initial conclusions of this work are the following:

- Two inspection methods are likely needed.

- Eddy current is likely suitable for surface examination while volumetric ultrasonic inspection can be used for tube bodies.
\end{abstract}

- Inspection under-water in a storage pool (EPI) is likely the best option for location in the JHR.

- Some automation and remote controls will be needed during the inspection process. The inspection area is quite large as the whole tube bodies will be inspected.

- Internal surfaces located between the nested tubes likely cannot be inspected for corrosion and therefore, sealing the space from oxygen and water will be likely be the best option.

- Experimental reference is a critical next step of the work to assess and qualify the inspection methods.

As the next step, CEA will continue discussions on requirements of the mock-ups: for eddy current inspection, a Zircaloy-4 planar specimen with artificial reflectors is needed. For ultrasonic reference, a representative mock-up of the cylinder with a weld and artificial $\operatorname{defect}(s)$ is needed. The mock-up testing will provide an experimental reference to CIVA calculations as simulations of this work have been performed with CIVA software, which is extensively used in the industry and research organizations in simulation of nondestructive control.

This study will allow further steps in the future, up to the qualification of inspection methods for JHR test devices.

Keywords - JHR, irradiation devices, NDT, NDE, periodical inspection, Non Destructive Examination, Ultrasounds, Eddy Currents, CIVA software

\section{INTRODUCTION}

THR irradiation test devices (so called ADELINE and MADISON) must undergo a periodic inspection every 40 months (French ESP(N) Regulation). The first step of inspection proposal concerns application of non-destructive methods for electron beam welds while examining the possible methods and locations that could be utilized. This initial study has been performed in collaboration between VTT Technical Research Centre of Finland Ltd and CEA. It was performed as VTT employee secondment at CEA Cadarache.

As the process of inspection planning has only just been started, it is pointed out that the methods chosen to studied here are not restrictive and are not presented as the only option. Lack of an aspect or a method should not be interpreted as having been considered and ruled out as insignificant or not suitable.

Further steps beyond, up to the qualification of inspection methods for JHR test devices, will include tests and simulations with CIVA software [1], which is extensively used in the industry and research organizations in simulation of nondestructive control.

\section{JHR TEST DEVICES}

In use, irradiation test devices are inserted into the vicinity of the reactor core and contain material or fuel samples. This report focuses mostly on the ADELINE device, which is shown in Fig 1. Orange and green weld markers show the approximate positions of the inner and outer tube welds.

The main body of the device consists of two vertical nested tubes - the main interest of the work described in this report. The thicker inner tube acts as a pressure vessel while the outer tube and the gas gap offer thermal insulation.

Once in use, due to deformations of thermal and radiation origins, these tubes are likely impossible to be separated (removal and re-assembly in a hot cell during inspection phase).

ADELINE material is Zircaloy-4 and MADISON device may have a stainless steel inner tube. The length of the inner tube is $3726 \mathrm{~mm}$, with inner tube diameter ranging from $38.8 \mathrm{~mm}$ to $66.0 \mathrm{~mm}$ and thickness ranging from 7.9 to 10.3 $\mathrm{mm}$. Gap width between the tubes ranges from 0.4 to $1.0 \mathrm{~mm}$. Outer tube outer diameter ranges from $64.6 \mathrm{~mm}$ to $108 \mathrm{~mm}$ and thickness from $4.0 \mathrm{~mm}$ to $9.7 \mathrm{~mm}$. ADELINE inner tube has three narrow electron beam welds and the outer tube has two $[3,4]$. Additionally, the tubes may be welded together from the 
top.

Machining and welding test information have been developed and qualified $[5,6]$.

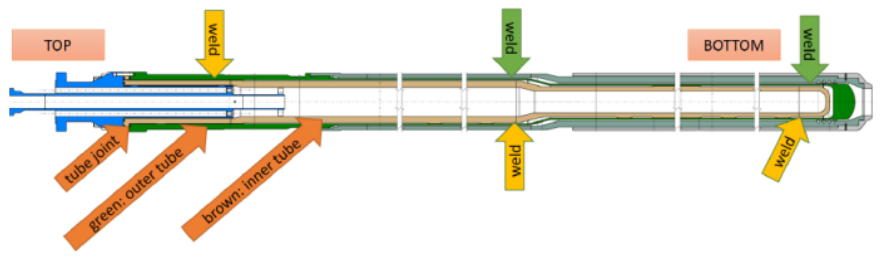

Fig. 1. ADELINE irradiation test device [2].

\section{PERIODICAL INSPECTIONS}

JHR irradiation test devices fall into N2 class of French nuclear pressure equipment regulation [7]. This criterion is for the equipment not falling into N1 criteria but activity release exceeding $370 \mathrm{GBq}$ in case of failure. Inspection interval of the devices is 40 months.

Only the inner and outer tubes of ADELINE device have to be inspected. Internal apparatus will have been dismantled in the hot cell before inspection operation.

At this stage, it is known that the inspection must respect the requirements of RCC-MRx [8]. As RCC-MRx is designed as guide for construction phase, it does not explicitly specify the requirements of periodical inspections.

According to radiographic inspection criteria (Table I), no crack type of defects are allowed. This definition does not specify the required accuracy of the inspection.

During this initial planning phase, it has been assumed (as best estimate) that the smallest defect that must be detected is $0.2 \mathrm{~mm}$ large.

As the RCC-MRx is not intended for inspection phase, it does not cover corrosion. For the purposes of this study, it has been assumed that the corrosion layer would be $0.05 \mathrm{~mm}$ thick.

TABLE I

RCC-MRX 7714.32: ACCEPTANCE CRITERIA FOR RADIOGRAPHIC EXAMINATION ALUMINUM AND ZIRCONIUM ALLOYS [8]

\begin{tabular}{|c|c|c|c|c|c|}
\hline $\mathrm{N}^{\circ}$ & $\begin{array}{l}\text { Imperfection } \\
\text { designation }\end{array}$ & $\begin{array}{c}\text { EN ISO } \\
\text { No6520-1 }^{\circ}\end{array}$ & Remarks & $\begin{array}{l}\text { Within } \\
\text { thickness }\end{array}$ & $\begin{array}{l}\text { Class } \\
\mathrm{N}_{2} \mathrm{Rx}\end{array}$ \\
\hline 1 & Crack & 100 & & $\mathrm{t} \geq 0.5 \mathrm{~mm}$ & Unacceptable \\
\hline 2 & Crater crack & 104 & & $\mathrm{t} \geq 0.5 \mathrm{~mm}$ & Unacceptable \\
\hline 3 & Porosity & 2011 & $\begin{array}{l}\text { Maximum dimensions of the } \\
\text { blowhole. }\end{array}$ & $\mathrm{t} \geq 0.5 \mathrm{~mm}$ & $\begin{aligned} & d<0.35 \text { or } 0.3 \mathrm{a} \\
& \max 5 \mathrm{~mm}\end{aligned}$ \\
\hline \multirow[t]{4}{*}{4} & \multirow{4}{*}{$\begin{array}{l}\text { uniformly } \\
\text { distributed } \\
\text { spherical } \\
\text { blisters }\end{array}$} & \multirow[t]{4}{*}{2012} & \multirow{4}{*}{$\begin{array}{l}\text { The defects are assessed } \\
\text { with respect to the projected } \\
\text { surface. } \\
\text { See the examples given in } \\
\text { standard EN ISO } 10042\end{array}$} & $0.5 \mathrm{~mm} \leq \mathrm{t} \leq 3 \mathrm{~mm}$ & $\begin{array}{c}A \leq 2 \% \\
L=100 \mathrm{~mm}\end{array}$ \\
\hline & & & & $3 \mathrm{~mm}<\mathrm{t} \leq 12 \mathrm{~mm}$ & $\begin{array}{c}\mathrm{A} \leq 4 \% \\
\mathrm{~L}=100 \mathrm{~mm}\end{array}$ \\
\hline & & & & $12 \mathrm{~mm}<\mathrm{t} \leq 30 \mathrm{~mm}$ & $\begin{array}{c}A \leq 6 \% \\
L=100 \mathrm{~mm}\end{array}$ \\
\hline & & & & $30 \mathrm{~mm}<\mathrm{t}$ & $\begin{array}{c}A \leq 8 \% \\
L=100 \mathrm{~mm}\end{array}$ \\
\hline 5 & $\begin{array}{l}\text { Clustered } \\
\text { porosity }\end{array}$ & 2013 & $\begin{array}{l}\text { The cluster is represented by } \\
\text { a circle of diameter } D A \\
\text { including all the porosities }\end{array}$ & $t \geq 0.5 \mathrm{~mm}$ & $\mathrm{DA}<20 \mathrm{~mm}$ \\
\hline 6 & Worm holes & 2016 & & $\mathrm{t} \geq 0.5 \mathrm{~mm}$ & $\begin{array}{c}1<0.3 \mathrm{~s} \text { or } 0.3 \mathrm{a} \\
\max 4 \mathrm{~mm}\end{array}$ \\
\hline 7 & $\begin{array}{l}\text { Oxyd } \\
\text { inclusions }\end{array}$ & 303 & $\begin{array}{c}\text { If many inclusions, } 11,12, \ldots+ \\
\qquad=11+12+\ldots\end{array}$ & $\mathrm{t} \geq 0.5 \mathrm{~mm}$ & $\begin{array}{l}\text { I }<0.5 \mathrm{~s} \text { or } 0.5 \mathrm{a} \\
\max 5 \mathrm{~mm}\end{array}$ \\
\hline 8 & $\begin{array}{l}\text { Tungsten } \\
\text { inclusions }\end{array}$ & 3041 & & $\mathrm{t} \geq 0.5 \mathrm{~mm}$ & $\begin{array}{c}1<0.3 \text { s or } 0.3 \text { a } \\
\quad \max 4 \mathrm{~mm}\end{array}$ \\
\hline
\end{tabular}

\section{A. Possible methods}

During the different working discussions, the following methods below were discussed in some capacities. Underlined are the ones that were ultimately chosen for the first part of the study:

\section{- Ultrasonic:}

o Volumetric,

o Guided waves;

- Eddy currents:

o Surface C-scan (perpendicular to the object),

o Bobbin probe (cylindrical);

- X-rays;

- Visual inspection;

o Dye penetrant.

As the internal apparatus of the device will be removed in the hot cell, it may be beneficial to perform a preliminary visual inspection before transporting the device to the next inspection location. This possibility will need to be discussed later as the inspection planning progresses.

Originally, also ultrasonic guided waves were intended to be studied but after receiving feedback from CEA Saclay experts, this was discarded as too lengthy study to be performed within the available time frame. A study of this kind would need to be performed in stages, starting from a highly simplified geometry and progressing towards real geometry.

From the very early stage of the study, it has been the impression that at least two methods are needed for the inspection. While ultrasonic volumetric inspection can be used for inspecting the tube bodies, it is not well suited for corrosion inspection. Eddy current examination, however, is very efficient in finding surface defects. Whether this extends to a small corrosion layer is discussed later in this report. In the present conditions, eddy currents do not penetrate more than a couple of millimeters into the tube so this method is devoted to surface-only examination.

\section{B. Inspection location and execution}

Once the test device is removed from the reactor core, sample holder of the device can be removed already in the reactor pool. From there, the device will be transported to the hot cell for disassembly of the internal parts. Possible inspection locations are the hot cell and the storage pool near the hot cells (Fig. 2). Both locations are accessible with existing transportation means.

Inspection in a hot cell would mean non-submerged inspection in a place where space is premium, whereas inspection in a storage pool would take place underwater and in an area where a dedicated inspection rig can be constructed. In ultrasonic inspection, a liquid film needs to be introduced between the probe and the inspected surface. This would not rule out hot cell inspection, but is a benefit of the in-pool inspection.

Due to these considerations, it is likely that inspection in a storage pool is the better option.

It is also a possibility that an existing bench could be adapted and used for these inspections. This approach has been recognized in the discussions but has not been studied. Inspection operations will need to be performed for both the inner and the outer tube. How the device and the probe would be handled has not been studied in detail but one possibility is: 
- Outer tube inspection: Device remains vertical and it will be rotated. The probe is introduced to the device radially from the side. The probe is capable of being moved vertically and radially in relation to the device.

- Inner tube inspection: A manipulator arm is inserted into the device which remains vertical. It is capable of moving vertically and radially in relation to the device. Either the manipulator arm or the device is rotated.

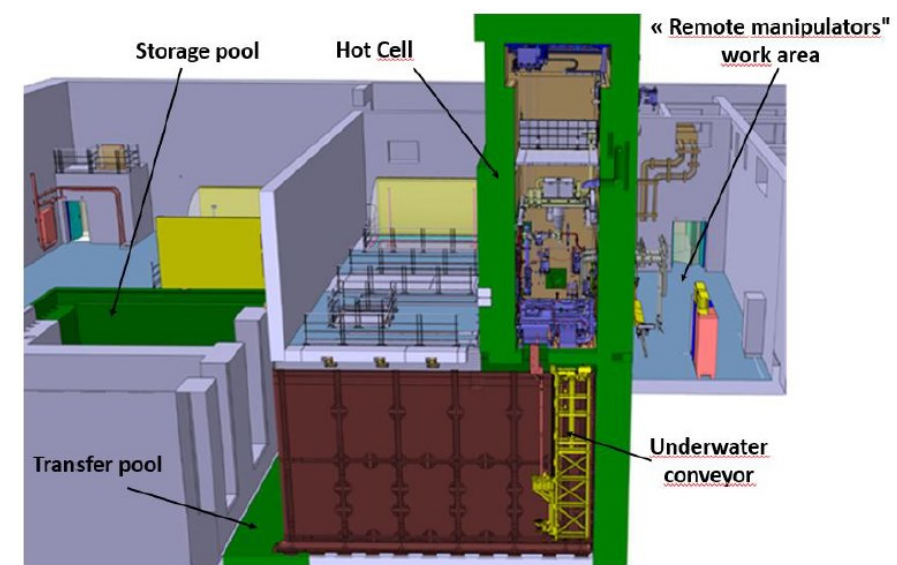

Fig. 2. JHR Storage Pool and Hot Cell.

Note: It is currently undecided what the final connection method of the inner and outer tubes is.

The inner and outer tubes can be welded together with similar means as other welds. For ADELINE, this weld (Fig. 3) should be relatively similar to inspect than the other welds. For MADISON, the connection would be between stainless steel and Zircaloy-4. The specifics of this inspection are not covered in this work but irradiation aspects may be significant [9].

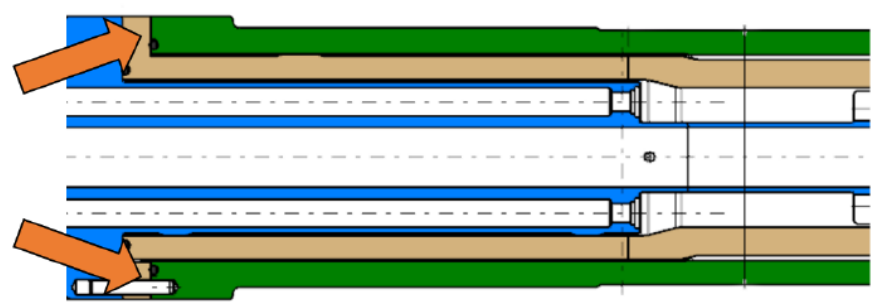

Fig. 3. Location of the optional end-weld.

\section{Simulations}

CIVA software version used in the simulations was CIVA_TECNA_2020-02-04.

\section{A. Geometry and used materials}

The simulations were done in a cylindrical geometry, within the cross section of each tube (Fig. 4). Diameter and wall thickness were taken from ADELINE device dimensions. Smallest inner tube diameter and largest wall thickness were used. Material in ultrasonic simulations was CIVA Zircaloy ready-made material with density changed to correspond RCC-MRx.

The following values were then used:

- bulk density : $6500 \mathrm{~kg} / \mathrm{m}^{3}$,

- transversal ultrasonic wave velocity: $2360 \mathrm{~m} / \mathrm{s}$ and

- longitudinal ultrasonic wave velocity: $4720 \mathrm{~m} / \mathrm{s}$.
In the eddy current simulations, Zircaloy-2 ready-made material was used:

- conductivity: $1.39 \cdot 10^{6} \mathrm{~S} / \mathrm{m}$ and

- relative permeability: 1.0

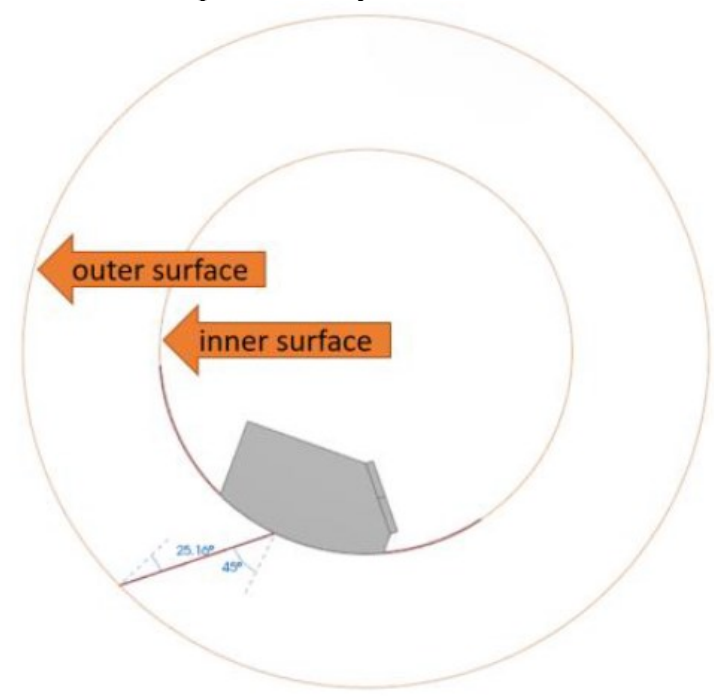

Fig. 4. Geometry used in the simulations.

\section{B. Ultrasonic simulations}

Ultrasonic testing is a family of non-destructive testing techniques based on the propagation of ultrasonic waves in the object or material tested. In most common applications, very short ultrasonic pulse-waves with center frequencies ranging from $0.1-15 \mathrm{MHz}$ are transmitted into materials to detect internal flaws or to characterize materials.

Such ultrasonic simulation can be performed using CIVA module which simulates the beam-defect interaction and predicts the amplitude and the time of flight of various echoes: direct echo, corner effect, tip diffraction echo, etc. It can also calculate echoes scattered back by the geometry (backwall, entry surface and interior specular interfaces echoes) and takes into account mode conversions.

Ultrasonic sensors chosen for this study are $2 \mathrm{MHz}$ frequency, $7 \mathrm{x} 7 \mathrm{~mm}$ and $10 \mathrm{MHz}, 8 \mathrm{x} 8 \mathrm{~mm}$ size. The $2 \mathrm{MHz}$ sensor was chosen as it represents a very common inspection frequency.

The sensor size was chosen as it produces a homogenous field into the inspected body when a flat sensor is used. It is, however, possible that this frequency will not allow detection of the smallest defects. The $10 \mathrm{MHz}$ was chosen since a similar probe is listed in a manufacturer catalog [10].

Both probes were used as contact probes. The used wedge length was $15 \mathrm{~mm}$, width $10 \mathrm{~mm}$ and height $10 \mathrm{~mm}$. Beam incidence angle to the tube body was 45 degrees.

In actual inspection, array sensors will be used. They were not used in this study since the use of single transducers was suitable for this first stage of study. Array sensors will be able to direct and focus the ultrasonic beam without mechanical means and this process is very fast. This will be highly beneficial for the inspection since not all type of defects cannot be detected from all angles (beam directing). Beam focusing will allow moving the strong focal spot throughout the inspected body. 
Beam verification is performed with a side drilled hole (SDH) as a reference reflector. SDH is a simple cylindrical shape (typically $1 \mathrm{~mm}$ or $2 \mathrm{~mm}$ diameter) with a flat base. It can be located at any distance from the sensor, within the depth of the piece to be controlled, perpendicular to the acoustic beam incidence to get an echo which can be used as a 'reference' state.

In practice, the characteristics of the different beams that will be used for the inspection are measured with side drilled holes. These measurements, simulated with CIVA and displayed on the next figures, allow evaluation of the beam characteristics like the refracted angle, the exit point, the beam focal point depth and the beam diameter at focal point. For example, for the $2 \mathrm{MHz}$ single planar probe, the amplitude echodynamic curve shows the weak amplitude variation of the transversal radiated beam with the depth (the variation is less that $2 \mathrm{~dB}$ from $2 \mathrm{~mm}$ depth (maximum amplitude) to $10 \mathrm{~mm}$ depth). Inspection geometry, a B-scan and an amplitude echodynamic curve are shown in Fig. 5 to 7.

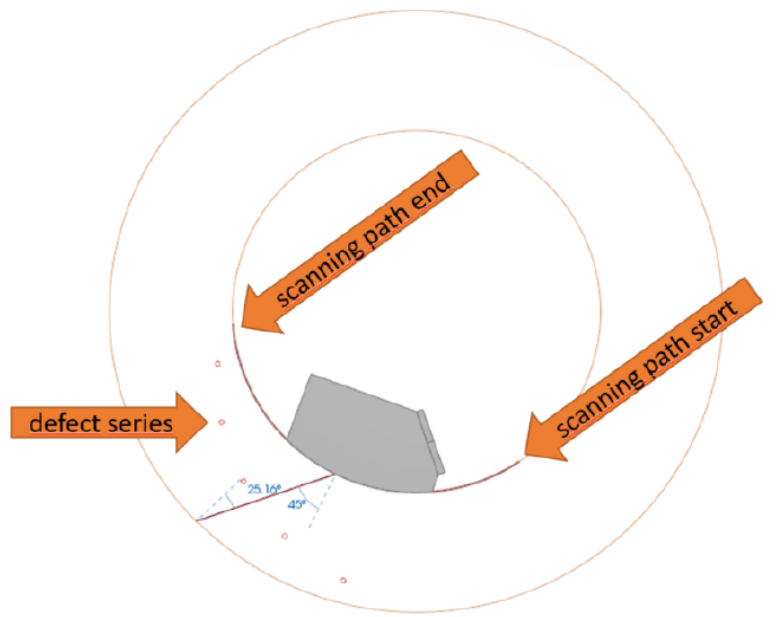

Fig. 5. Geometry in the inspection simulation and defect positions.

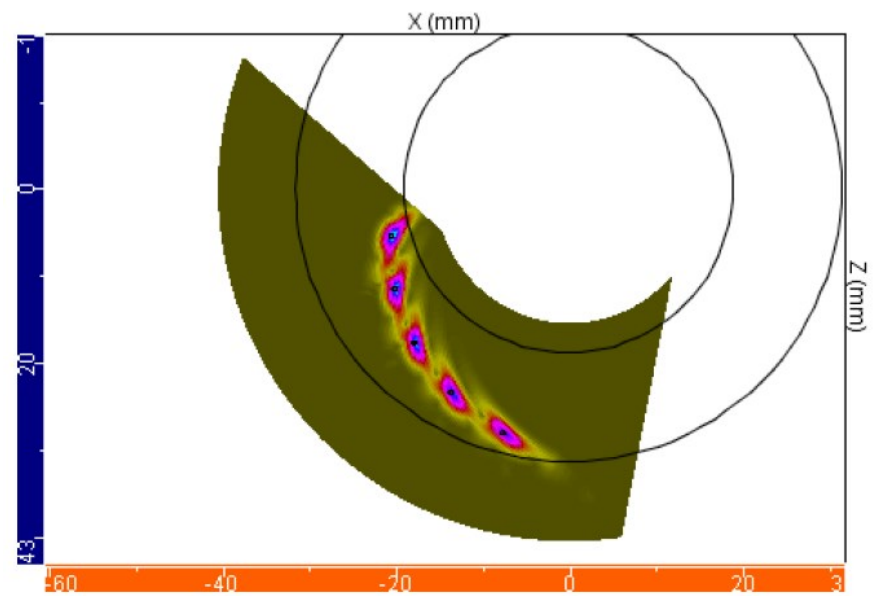

Fig. 6. B-scan of a SDH defect series.

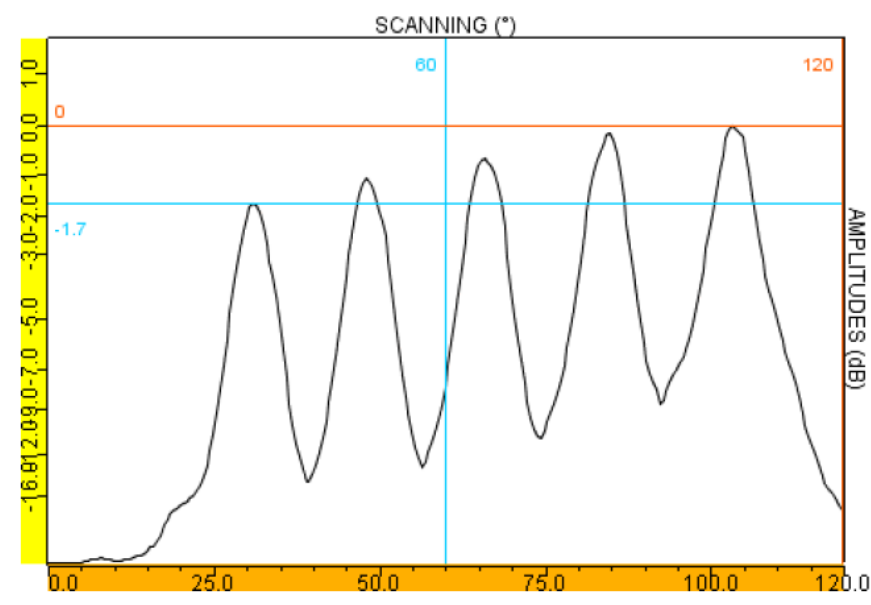

Fig. 7. Amplitude echodynamic curve.

Ultrasonic echoes identification is made considering that, even if only transversal direct waves are radiated into the specimen, mode conversion will occur at the back wall or defects leading to a variety of echoes (see Fig. 8). This is especially relevant in this case as the back-wall is curved. It will likely not be possible to direct longitudinal echo out of the tube body. CIVA simulations can help to predict the expected inspection echoes. Two examples are given in Fig. 9 and in Fig. 10.

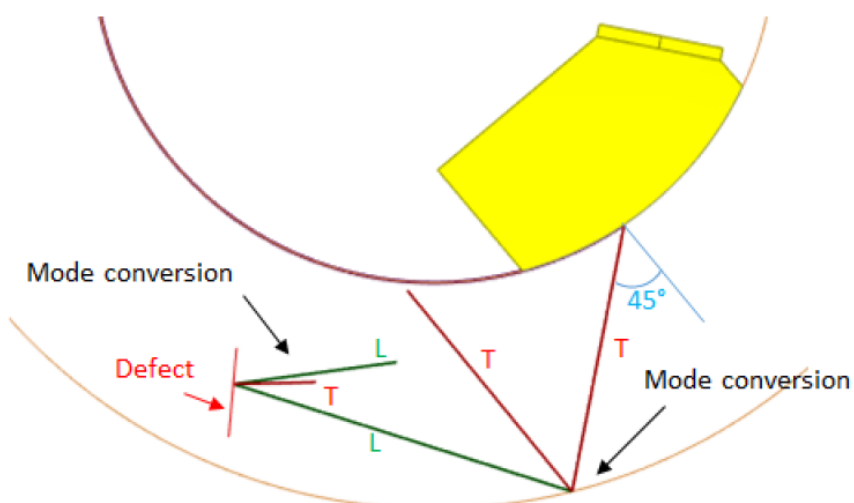

Fig. $8 . \mathrm{T} 45^{\circ}$ radiated beam, mode conversion on the back-wall and on the defect.

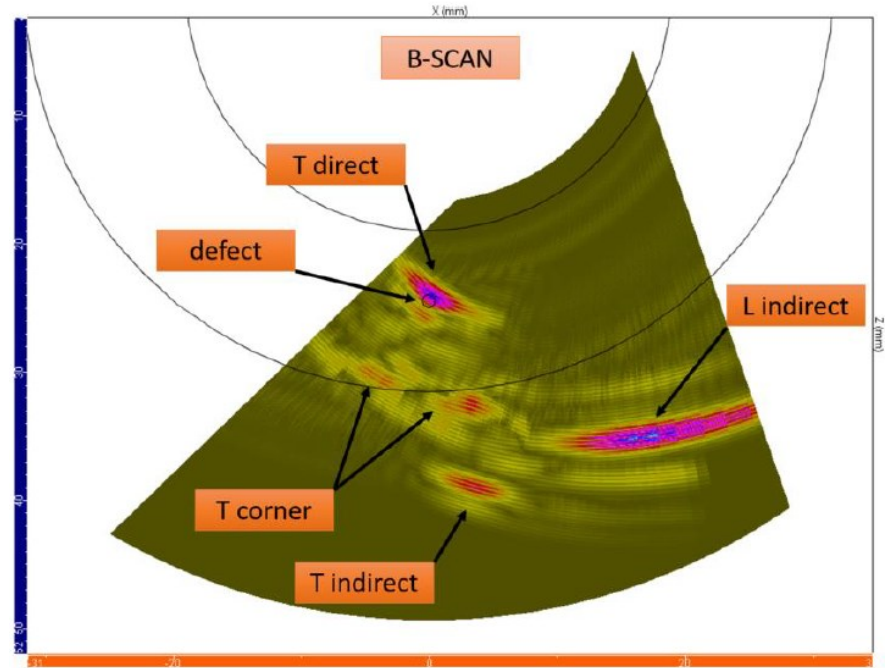

Fig. 9. Identified echoes: $1 \mathrm{~mm} \mathrm{SDH}$ at $5 \mathrm{~mm}$ depth. 


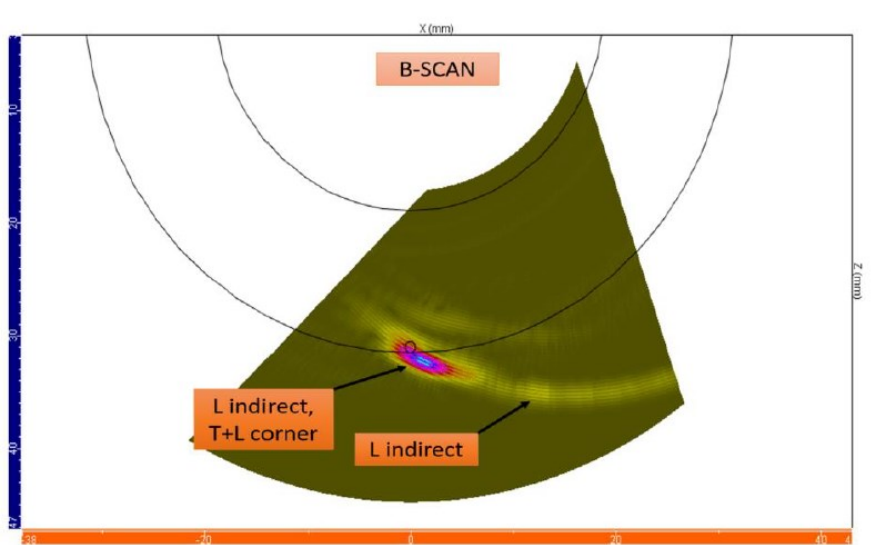

Fig. 10. Identified echoes: $1 \mathrm{~mm} \mathrm{SDH}$ at back wall.

For beam focusing, $2 \mathrm{MHz}(7 \times 7 \mathrm{~mm}$ rectangular) and $10 \mathrm{MHz}$ $(8 \times 8$ rectangular) spherical sensor beam profiles were calculated in order to see the range of possible focus. For the $2 \mathrm{MHz}$ probe, $10 \mathrm{~mm}$ spherical radius produces a $1.6 \mathrm{~mm} \mathrm{x}$ $4.9 \mathrm{~mm}$ focal spot $(-3 \mathrm{~dB})$ in the inner surface. Increasing the spherical radius will not move the focal point (strongest point of the beam) to the outer surface but instead the beam turns effectively into a flat sensor beam. All of the tube body is, however, in the focal spot area from $50 \mathrm{~mm}$ radius onward. Spherical $200 \mathrm{~mm}$ radius produces a $4.0 \mathrm{~mm}$ times $17.5 \mathrm{~mm}$ focal spot. The beam profiles are shown in Fig. 11.

For the $10 \mathrm{MHz}$ probe, $10 \mathrm{~mm}$ spherical radius places a $0.3 \mathrm{~mm}$ times $1.0 \mathrm{~mm}$ focal spot into the inner surface. Using $25 \mathrm{~mm}$ spherical radius, the focal spot is at the other surface and its size is $0.7 \mathrm{~mm}$ times $5.7 \mathrm{~mm} .10 \mathrm{MHz}$ beam profiles are shown in Fig. 12.

These simulated beams show that, for a given probe and frequency, it will be possible to compute the radiated beam with CIVA in order to check the insonification of the specimen thickness and the focal spot dimension and adjust the probe's parameters and frequency if necessary.

With the use of array sensors focusing will be much easier, as they provide wide possibility of focus.

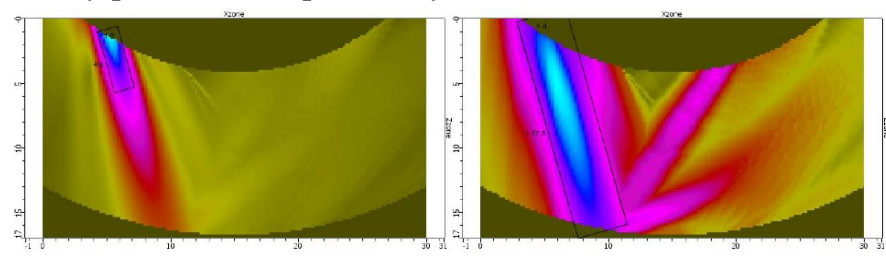

Fig. 11. Beam profiles: $2 \mathrm{MHz}, 7 \times 7 \mathrm{~mm}$ rectangular probe, spherical focus $\mathrm{r}=10 \mathrm{~mm}$ (left) and $200 \mathrm{~mm}$ (right).

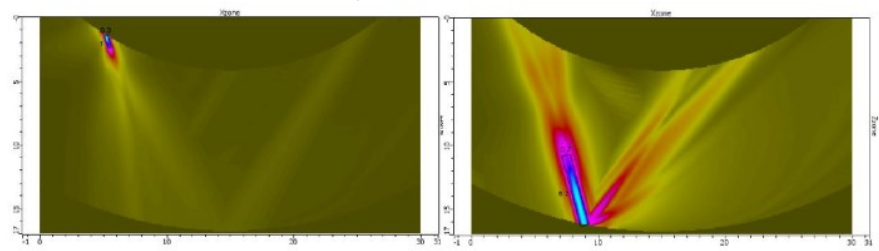

Fig. 12. Beam profiles: $10 \mathrm{MHz}, 8 \times 8 \mathrm{~mm}$ rectangular probe, spherical focus $\mathrm{r}=10 \mathrm{~mm}$ (left) and $25 \mathrm{~mm}$ (right).

\section{Eddy current simulation}

Eddy-current testing is one of many electromagnetic testing methods used in non-destructive testing making use of electromagnetic induction to detect and characterize surface and sub-surface flaws in conductive materials. It is why eddy current control simulation has been done in order to evaluate the detection of corrosion and surface defects. Conventional coil sensor has been chosen.

As not all needed geometrical details were available in manufacturer catalogues, a reasonable assumption for a sensor was identified.

A representation of a single eddy current simulation coil is shown in Fig. 13.

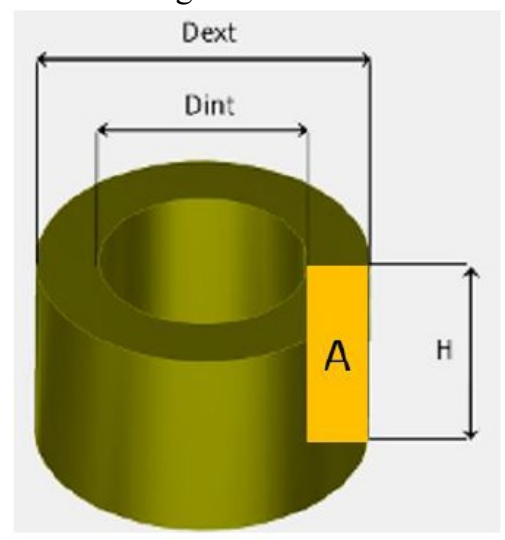

Fig. 13. Eddy current coil dimensions.

In actual examination, many of these coils would be used in array setup. Unlike ultrasonic array probes, in evaluation of defect response, eddy current probes gain only larger inspection area from array use and a simulation of a single probe is sufficient for determining the response.

It is assumed here that half of the coil area is conductive material (wire). Area of a single coil wire is then calculated as follows:

$$
A_{\text {s. coil }}=\frac{0.5 \cdot H \cdot(\text { Dext }- \text { Dint }) / 2}{n_{\text {coil }}},
$$

where $A_{\text {s.coil }}$ is the area of a single coil wire, $H$ is the height of the coil, $D_{\text {ext }}$ is the coil external diameter, $D_{\text {int }}$ is the coil internal diameter and $n_{\text {coil }}$ is the number of turns in one coil.

Usually, 5 amperes per square millimetre can be put through a single coil wire. Therefore maximum current for the simulation is:

$$
I \max =5 \cdot A \text { s. coil , }
$$

where $I_{\max }$ is the maximum usable current in the simulation. Using values shown in Table II, we end up with maximum usable current of $28 \mathrm{~mA}$. Value $25 \mathrm{~mA}$ was chosen for simulations.

TABLE II

EDDY CURRENT SIMULATION COIL VALUES

\begin{tabular}{|l|l|l|l|}
\hline Acronym & Value & Unit & Note \\
\hline$H$ & 1.5 & $\mathrm{~mm}$ & Height of the coil \\
\hline$D_{\text {ext }}$ & 2.0 & $\mathrm{~mm}$ & Coil external diameter \\
\hline$D_{\text {int }}$ & 0.8 & $\mathrm{~mm}$ & Coil internal diameter \\
\hline$n_{\text {coilt t. }}$ & 80 & - & Number of turns in one coil \\
\hline A & 0.9 & $\mathrm{~mm}^{2}$ & Area of the coil bundle \\
\hline$A_{\text {s.coil }}$ & 0.005625 & $\mathrm{~mm}^{2}$ & Area of a single coil wire \\
\hline$I_{\text {max }}$ & $\begin{array}{l}0.028125 \\
(25 \mathrm{~mA} \text { chosen })\end{array}$ & A & Maximum current in eddy current simulation \\
\hline
\end{tabular}


Another type of eddy current sensors could be used (bobbin probe), having a much larger diameter, approximately the diameter of the tube to be controlled. It would be moved along (for external inspection) or within (for internal inspection) the tube, giving a more global information on the specimen state.

For simulation, parametric variations of lift-off were performed at $1 \mathrm{MHz}$ frequency. In these simulations, a scanning pattern shown in Fig. 14 was used. As result a C-scan and a maximum amplitude of each permutation were obtained. Liftoff values ranged from $0 \mathrm{~mm}$ to $1.8 \mathrm{~mm}$ in $0.2 \mathrm{~mm}$ increments.

Defects in these simulations were vertical and rectangular. The defect sizes and used mesh points are shown and explained in Table III and Fig. 14. Fig. 15 visualizes the loss of resolution when a higher lift-off is used. The results of the parametric variations are shown in Fig. 16.

As the noise of close to sensor electronics is in the range of $1 \mathrm{nV}$, it is difficult to detect the signals with amplitudes of the same value. That is why the defects detection limit is defined as $1 \mathrm{nV}$ in amplitude. All of the simulation results are over this value.

In this regard, these results are promising even for corrosion detection ( $0.05 \mathrm{~mm}$ thickness) but no conclusions should be drawn at this early state. Experimental testing with a mock-up will give a reference for future simulations.

As for the preferred value of lift-off, a smaller value is better. How small this value can be will likely depend on robotic and mechanical aspects. If contact probes cannot be used, handling accuracy will define a limit for the lift-off. In order to have the possibility to move the sensor inside the tube without it damaging the tube, lift-off range should be 0.1-0.2 mm.
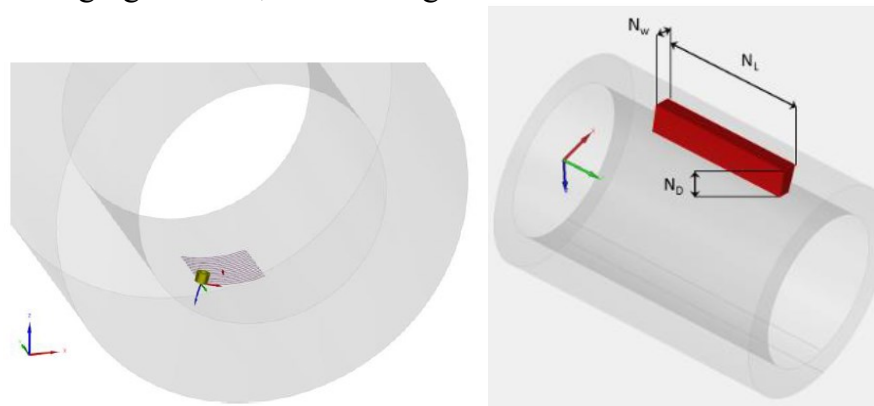

Fig. 14. Scanning pattern in eddy current simulations with geometrical explanation of Table III variables.

TABLE III

DEFECT MESH POINTS IN THE EDDY CURRENT LIFT-OFF VARIATION

\begin{tabular}{|c|c|c|c|c|}
\hline & $\begin{array}{c}\mathrm{NL} \times \mathrm{ND} \times \mathrm{NW} \\
0.5 \times 0.5 \times 0.1 \mathrm{~mm}\end{array}$ & $\begin{array}{c}\mathrm{NL} \times \mathrm{ND} \times \mathrm{NW} \\
0.2 \times 0.2 \times 0.1 \mathrm{~mm}\end{array}$ & $\begin{array}{c}\mathrm{NL} \times \mathrm{ND} \times \mathrm{NW} \\
0.1 \times 0.1 \times 0.1 \mathrm{~mm}\end{array}$ & $\begin{array}{c}\mathrm{NL} \times \mathrm{ND} \times \mathrm{NW} \\
0.5 \times 0.05 \times 0.1 \mathrm{mr}\end{array}$ \\
\hline Mesh points & $10 \times 10 \times 2$ & $4 \times 4 \times 2$ & $2 \times 2 \times 2$ & $10 \times 1 \times 2$ \\
\hline
\end{tabular}

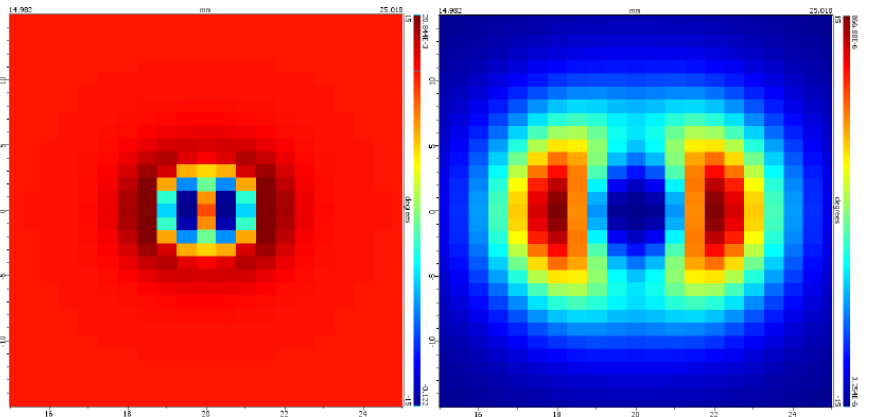

Fig. 15. Eddy current C-scan, $0.5 \mathrm{~mm} \times 0.5 \mathrm{~mm} \times 0.1 \mathrm{~mm}$ defect, real part : 0.2 $\mathrm{mm}$ lift-off (left C-scan), $1.8 \mathrm{~mm}$ lift-off (right C-scan).

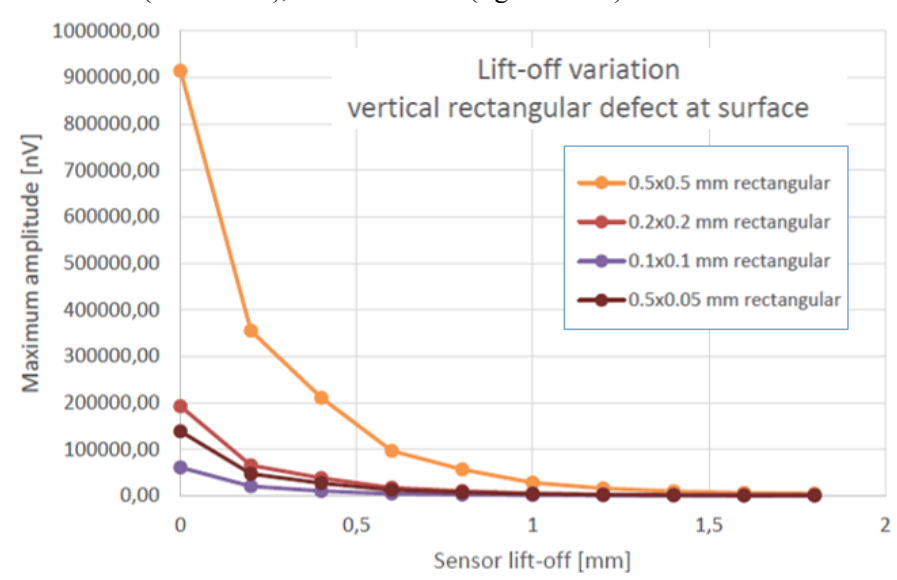

Fig. 16. Eddy current maximum amplitudes in lift-off variation simulations (defect width $=0.1 \mathrm{~mm}$ ).

\section{PROCEEDING TO MOCKUP TESTING}

Proceeding to experimental phase will be mandatory for establishing the NDT methods qualification. CIVA simulations are performed in two steps: a first step before experimental phase for guiding the preliminary choice of NDT methods and associated sensors, and a second step after experimental phase for ranging various relevant parameters and confirming methods and sensors, as not all aspects of inspection could be taken into account in CIVA simulations. The final sensor or sensors will need to be determined.

For Eddy current inspection, a Zircaloy-4 calibration block is needed. Reference defects will need to be introduced and their sizes to be decided.

As of now, the Eddy current inspection is suspended and the joint effort is focusing on the volumetric ultrasonic inspection: two representative mock-ups of the cylinders, each of them including a weld and artificial defects (reflectors) have been manufactured (Fig. 17). Some side drilled holes and slots will be machined within the molten area of the weld, and also in the Heat Affected Zone, as reflectors for inspection tests.

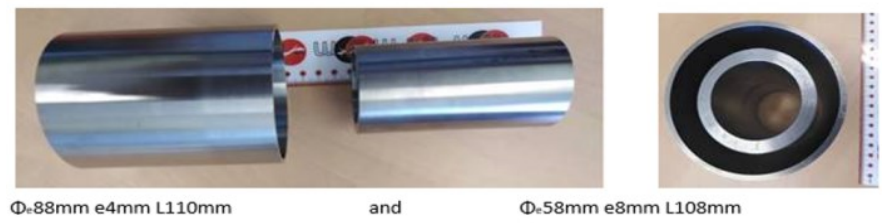

Fig. 17. Representative mock-ups with Electron Beam weld join 
CEA will perform in water tests with a linear phased array (128 elements at $15 \mathrm{MHz}$ ) and VTT will make the corresponding CIVA simulations.

\section{CONCLUSIONS}

Conclusions of this work can be summarized as follows (2020 position):

- Two inspection methods are likely needed:

o Eddy current is likely suitable for surface examination o volumetric ultrasonic inspection can be used for tube bodies. -Under-water storage pool is likely the best inspection location. - Since it is assumed that all of the tube body has to be inspected with the same resolution as the welds, area to be inspected becomes rather large. Therefore, it is likely that some level of automation in the scanning process is needed.

- It is very likely that the surface between the inner and outer tubes cannot be inspected for corrosion issues. If tubes were to be welded to each other and the space between would be filled with inert gas, probability of corrosion occurrence would be low.

- Experimental reference as the next step is critically important.

As the next step (in 2021), CEA and VTT are continuing the inspection work with two representative mock-ups (with Electron Beam welds). Artificial defects have been specified (side drilled holes and slots).

Under water tests will provide an experimental reference to CIVA calculations.

Proceeding to experimental phase is mandatory for establishing the NDT methods qualification. CIVA simulations are performed in two steps: a first step before experimental phase for guiding the preliminary choice of NDT methods and associated sensors (linear phased array at about $15 \mathrm{MHz}$ ), and a second step after experimental phase for confirming methods and sensors, as not all aspects of inspection could be taken into account in simulations.

\section{REFERENCES}

[1] CIVA NDT simulation software. Available: http://www.extende.com/civain-a-few-words

[2] F. Delassalle, "Minimal and maximal values for diameter, thickness and gas/water gap for each device section latest device", March 2020, unpublished

[3] RJH - ADELINE - Mecanics - Assembling internal tube device, A3 Drawing, December 2018, unpublished

[4] RJH - ADELINE - Mecanics - Assembling internal tube device, A3 Drawing, December 2018, unpublished

[5] Test program for the machining and assembly of Zircaloy, September 2019, TESTE society, unpublished

[6] Electron beam weld test on a Zircaloy mockup, October 2019, BODYCOTE-TECHMETA society, unpublished

[7] French Nuclear Pressure Equipment Regulation, 2005

[8] Design and Construction Rules for Mechanical Components in hightemperature structures, experimental reactors and fusion reactors, RCCMRx. Available: AFCEN, 2018

[9] S. Gaillot, "RJH Preliminary estimation of radioactive doses within irradiation device tubes during mandatory periodical inspection”, 2017, unpublished

[10] Olympus NDT Solutions, Small-Footprint Probes. Available: https://www.olympus-ims.com/en/probes/small-footprint/ 